\title{
Construction and validation of the remote teaching quality perception scale in the COVID-19 pandemic: an exploratory factor analysis and item response theory approach.
}

\section{Rafael da Silva Fernandes ( $\square$ rafasfer2@ufra.edu.br)}

Universidade Federal Rural da Amazônia: Universidade Federal Rural da Amazonia https://orcid.org/0000-0002-3035-8025

Rosana Maria do Nascimento Luz

Universidade Federal Rural da Amazônia: Universidade Federal Rural da Amazonia

Daniela Castro dos Reis

Universidade Federal Rural da Amazônia: Universidade Federal Rural da Amazonia

Marc Augusto Lima da Luz

Universidade Federal Rural da Amazônia: Universidade Federal Rural da Amazonia

Gabriella Vitorino Guimarães

Universidade Federal Rural da Amazônia: Universidade Federal Rural da Amazonia

Antônio Cezar Bornia

Universidade Federal de Santa Catarina

Dalton Francisco de Andrade

Universidade Federal de Santa Catarina

\section{Research Article}

Keywords: Psychometric assessment, teaching assessment, measuring tool, student perspectives, teaching quality

Posted Date: January 31st, 2022

DOI: https://doi.org/10.21203/rs.3.rs-1269691/v1

License: (c) (i) This work is licensed under a Creative Commons Attribution 4.0 International License. Read Full License 


\section{Abstract}

The biosafety protocols adopted to ensure social distancing between people during the COVID-19 (SARSCoV-2) pandemic changed social interaction behavior and led educational institutions to adopt the emergency remote teaching format. To understand the impact on the learning process, this article aims to develop and build a measurement tool to measure the perception of students regarding the adequacy of remote teaching, offered by the Federal Rural University of the Amazon (UFRA), to the detriment of onsite teaching previously adopted in the context of the COVID-19 pandemic, this being the latent trait to be measured. For content-based validation, the study conducted three phases: 1) initial construction of the measurement tool and literature search; 2) conducting focus groups with students; and 3) analysis by judges to outline factors and potential items. The tool presented for the content validity index a mean of $94.16 \%$ of acceptance per item and values above $93.43 \%$ of acceptance for the factors and domains. For validation based on the internal structure, this study applied the concepts of item response theory, factor analysis, and dimensionality. The overall precision of the tool scores was analyzed using Cronbach's alpha coefficient, whose value obtained was $96.64 \%$, indicating high precision. Besides the coefficient, the precision of the tool was analyzed through the information function of the IRT test, whose result is in the interval between (-1.5 and 2.5) approximately. Finally, a standardized measurement scale was created with the metric $(0,10)$ from 501 respondents, and it was possible to observe that a profile associated with a perceived negative loss of teaching quality is positioned at levels lower than -10 and referring to that $30.2 \%$ of students, at the levels ( -5 to 5$)$, are more likely to be positioned at a level of equivalence and refer to $45.7 \%$, and at higher levels to 7 , with $24.1 \%$ of the respondents, are associated with a positive perceived gain in teaching quality.

\section{Introduction}

Due to the COVID-19 pandemic, declared in March 2020 by the World Health Organization (2020), Universities in several countries have adopted emergency remote teaching, including those in Brazil (Aguilera-Hermida, 2020; Ali, 2020; Buttler et al., 2021; Chiou, 2020; Hofer et al., 2021; Secundo et al., 2021)

The Federal Rural University of the Amazon - UFRA had its Academic Calendar (CA) suspended on March 19, 2020. Through Resolution No. 571-Consepe/2020, the Supplementary Academic Period (PLS) was regulated. Curricular components and other academic activities were offered in a reduced period (8.5 weeks) without compromising the course load contained in the Pedagogical Projects of the Courses PPC. In this way, onsite teaching was replaced by emergency remote teaching, with classes held synchronously and asynchronously. In January 2021, regular academic periods were re-established but followed the same format.

Some studies on remote teaching were carried out, including the practice of psychological assessments, reinforcing the importance and need for research that demonstrates rigor, ethics, and safety (Marasca et al., 2020), the investigation of the perception that university students had about emergency online 
education (adoption, use, and acceptance), and its quality (Aguilera-Hermida, 2020; Hofer et al., 2021; Iglesias-Pradas et al., 2021; Moser et al., 2021; Secundo et al., 2021; Shim \& Lee, 2020). Other studies point to the psychological impacts suffered by higher education students in the face of this new reality resulting from the fear of Covid-19 (Buttler et al., 2021; Cavalheiro \& Sticca, 2020).

Few publications analyzed emergency remote teaching in Universities (De la Fuente et al., 2021; QuispePrieto et al., 2021; Ribeiro \& Corrêa, 2021). This fact can be based on two assumptions: [1] The first time that universities are experiencing this type of change in the teaching format, called Emergency Remote Teaching (ERT), which differs in the meaning of distance learning, offering temporary instructional support developed with less planning time (Hodges et al., 2020; Mohmmed et al., 2020; Whittle et al., 2020) and; [2] Note that research focused on the impact of ERT and directed to the literature on Education, has not used psychometric procedures with an approach focused on the latent trait theory and without validation carried out with the support of measurement fundamentals in mental health.

Furthermore, no studies or research were identified that measured the quality of adequacy of remote teaching, nor that the methodology had aspects related to psychometrics, a method applied only in a few countries using structural equation modeling (Buttler et al., 2021). Thus, the studies cited provided a longitudinal bibliometric framework, with themes related to psychometry, measurement, construction of measurement tools and their validation, latent trait, quality of remote teaching, and covid-19, which ultimately subsidized and guided the construction of a valid measurement tool for this research.

Therefore, there was a need to assess students' perception in relation to the teaching model to which they were submitted in this new pandemic reality. For this, a tool to measure emergency remote teaching was developed, based on three poles, namely: theoretical, empirical (experimental), and analytical (statistical) procedures. The assessed aspects were related to class dynamics, their own adequacy for remote teaching, structure, regulation of remote teaching, own resources, study environment, external incentives, and their efforts, relationships, and personal motivations.

In this context, it is assumed that teaching quality will be lost, mainly due to the conditions for conducting a fully online semester in 2020. This work aimed to develop, build, and validate a measurement tool to measure the perception of students regarding the adequacy of remote teaching offered by the Federal Rural University of the Amazon (UFRA), to the detriment of onsite teaching adopted before the new context. Specifically, this work performs a double validation.

In this context, this study has as methodological objective to propose a methodology based on the procedure of elaborating new tools reviewed by (Coluci et al., 2015) and of the fundamentals of measurement in mental health (Gorenstein \& Wang, 2016; Pasquali, 2017). Subsequently, content-based validation is performed.

For validation based on the internal structure, this study applied the concepts of item response theory, factor analysis, and dimensionality. Thus, given the model determination, unidimensional or multidimensional, it is possible to describe a student's probability of responding to an item, given their 
perception (latent trait). In other words, the construct enables the construction of a standardized measurement scale that measures the students' perception in the multiple perspectives of an educational environment.

This goal is formalized into the following research questions (RQs):

$R_{Q_{1}}$ : How is the students' perception in relation to the teaching model to which they were submitted in this new pandemic reality?

$\mathbf{R Q}_{2}$ : How different factors influence the distance education environment and which, in turn, generates a negative, neutral, or positive perception associated with the quality of distance learning?

$R_{Q_{3}}$ : By presenting a conceptual structure of the main concepts, terms and expressions used within the context of Emergency Remote Teaching, the measurement tool can be modeled by a unidimensional structure?

$\mathbf{R Q}_{4}$ : The construct proposed is enough to measure of the latent trait and assessing the quality of adequacy of the emergency remote teaching offered?

However, this article does not intend to present conclusions about the perspectives of UFRA students but only to use the sample to create the scale of perceived adequacy of remote teaching to the detriment of onsite teaching.

\section{Literature Review}

\section{Practical motivating situation}

The concern and relevance in relation to the exceptional moment that the world is experiencing in the face of the Covid-19 pandemic reinforce the observation that universities must create alternatives in all sectors they operate.

Thus, after the suspension of the Academic Calendar (CA) 2020.1 on March 19, 2020, and to seek alternatives to face the situation in question, the Federal Rural University of the Amazon - UFRA, located in Northern Brazil, headquartered in Belém/PA and five more campuses located in the cities of Parauapebas/PA, Paragominas/PA, Tomé-Açu/PA, Capitão Poço/PA, and Capanema/PA, began the process of planning for teaching. Through Technical Note No. 01/2020 - PROEN/UFRA, dated March 26, 2020 , the institution encouraged professors to conduct academic activities through the SIGAA platform to maintain virtual contact with their students, such as recommending topics for reading and activities.

Considering Resolution No. 567-Consepe/2020, of July 01,2020 , UFRA created a special committee through Ordinance No. 943 of July 06, 2020. This committee proposed an alternative academic calendar, called the Supplementary Academic Period (PLS), with the offer of curricular components in emergency and temporary digital format, seeking above all to keep the university active, especially from the point of 
view of undergraduate education, where students and professors maintain social, cognitive, and emotional interaction.

The Supplementary Academic Period (PLS - 2020.5) consisted of a reduced period of 8.5 weeks, which aimed to minimize the impacts of the long-term suspension of academic activities due to the COVID-19 pandemic, enabling the offer of curricular components and other academic activities in a non-presential format, synchronously or asynchronously, using information and communication technologies (ICT). It is noteworthy that the PLS - 2020.5 did not reduce the course load of the curricular components but made the shift and the offer period more flexible. The assessment procedures fall under a strand that aims to assess the knowledge acquired by students throughout their training. On the other hand, subjective aspects and several factors directly impact the student's learning beyond the course's own knowledge, especially in higher education. Over the years, some factors have been investigated, such as reasons related to dropout, social and economic impacts, study home environments, among others related to the student's experience in the academic environment (Ambiel, 2015; Buttler et al., 2021; Newton, 2017; Sindhu et al., 2019).

\section{Latent trait measured and assessment design}

This study analyzes students' perspective and constitutes property for assessing the teaching quality. Specifically, the object or psychological system to be represented is the latent trait "students' perceived the adequacy of remote teaching, offered by the Federal Rural University of the Amazon (UFRA), to the detriment of onsite teaching previously adopted in the context of the COVID-19 pandemic". The properties or attributes of an object are the various aspects that characterize it and must be defined to elaborate a tool.

Thus, given the latent trait, this can be measured by the adequacy attribute and is associated with a negative, neutral, or positive perception, considering the following aspects of social and academic systems regarding: class dynamics, their own adequacy to remote teaching, structure, and regulation of remote teaching, its own resources, study environment, and external incentives and, finally, its efforts, relationships, and personal motivations. As an example, the following conceptual model is presented in Figure 1:

This psychological attribute can be understood as a measure of the latent trait of assessing the quality of adequacy of remote teaching offered by UFRA, which, in turn, is not something directly identifiable or observable. Thus, there is a need to develop a construct that expresses the reality observed indirectly through other variables or factors that can be observed and are related to the subject of interest to be measured (Pasquali, 2017).

The concept of adequacy or perceived adequacy, in this work, refers to the idea of a search for criteria that measure the similarity between knowledge and the object that corresponds to it. Therefore, considering the remote educational environment, in which the student is inserted and incorporating the 
academic and social integration aspects of the longitudinal model of dropout of (Tinto, 1975), the hypothesis of the proposed conceptual model (Figure 1) is that there is a set of factors that directly influence this environment and which, in turn, generates a negative, neutral, or positive perception associated with the quality of remote teaching. Thus, given the impact of these factors, the student's assessment will generate perceived adequacy worse, equivalent, or better than in onsite teaching to measure the quality of adequacy of emergency remote teaching.

Given the recognition that students' perceptions of the educational environment directly influence their learning, (Roff et al., 1997) define the educational "environment" or "climate" as any learning experience that influences students' motivation to learn, thus affecting their attitudes, values, and related behaviors to a learning task. In this way, measuring the quality of teaching from the student's perspective corroborates the justification and contribution of this work to the literature.

According to (Burleson \& Thoron, 2014), the assumption of a good educational environment must include base factors that can meet the following aspects: 1) the physical needs of students and associated ergonomic conditions; 2 ) the security and confidence of students regarding the conduct of teaching/learning activities; 3 ) engagement, a sense of belonging in their human development process and the importance of the role of professional practice to promote social, political, economic, cultural, and environmental changes in the student during the academic period; 4) self-esteem, related to the importance of providing constructive feedback and given the context of the COVID-19 pandemic.

\section{Research Methodology}

Application Context

The research was conducted in the Amazon, Northern Brazil, in the state of Pará, where the Federal Rural University of the Amazon (UFRA) is located, which is headquartered in the State Capital, Belém, and has five campuses in the following municipalities: Tomé-Açu, Paragominas, Capanema, Capitão Poço, and Parauapebas. In Figure 3, the map represents the sample distributed in the respective Campuses.

Although every technical care was taken in determining the sample size and its selection, defining the sampling model, fixing the maximum sampling error, determining the confidence coefficient, sample selection method to avoid the occurrence of trends, it justifies the determination of data collection by campuses/course. Thus, at first, it was necessary to understand the research respondents' profiles to build the perception of students proposed in the latent trait.

Operationalization and validation of the content procedure

The procedure for creating, adapting, and validating the items was based on the multi-criteria model (Nickel et al., 2010). The operationalization and analysis steps of the items are described in detail as follows: 
- Step 01: Elaboration and initial description of the items: a set of items is elaborated based only on the experiences and suggestions of the authors of this article. This process refers to the identification of customer requirements for the product, that is, it is related to the collection of characterization needs from multiple perspectives, factors, and latent traits. Notably, such needs were somehow mentioned or indicated by students and professors throughout the remote academic periods.

- Step 02: Grouping and classification of items: refers to the distribution of needs into primary elements of factor specification, that is, the process of targeting the items to the respective factor. When a larger set of items is presented, grouping and classifying such needs is useful to check for similar items, eliminating repetitions and unimportant needs.

- Step 03: Definition and ranking of factors: this refers to the understanding of the researchers in this study regarding the criteria of clarity, relevance or representativeness, and scope and is called internal validation. Thus, through a value tree, it is possible to determine the requirements for the factors to have a deeper and more precise understanding of what should be of concern in the context in question.

- Step 04: Target question and item conversion: as a simple explanation for intuitive items, it is necessary that, when a satisfactory answer to a difficult question is not quickly found, it is necessary to establish a target question, which is the assessment that the research tends to produce and transform it into an appropriate (or empirical) question which, in addition to framing the category of answers, is a simpler question that is answered instead of the target question. The process of converting items, after grouping and classification, obtains clearer and simpler descriptions, that is, measurable questions or expressions. Furthermore, this conversion consists of a set of goals, each of which can be seen as a means to an end or the cause of an effect.

- Step 05: External validation of items: after defining and ranking the items, external validation was required, which was performed in three different ways:

i. literature review of items validated in other measurement tools and that, following the previous steps, can be fitted to the pilot measurement tool;

ii. conducting rounds of focus groups, with the participation of about 5 students of the institution, in order to understand the difficulty of understanding the items by the target interviewees, that is, the items ask or empirically approach the target question;

iii. application of a form for more than five experts working in the field of education and/or psychometrics, so that the minimum criteria necessary for the set of items of each factor of the measurement tool are dimensioned. The domains are initially checked, considering clarity, relevance or representativeness, and scope. Then, each of the factors and items is assessed following the same criteria to verify whether each domain is adequately covered by the set of factors and items. Besides, we consider an assessment of the tool's organizational structure, aspects of social and academic integration, and impact on the student's academic environment. 
- Step 6: Pre-test procedure: The pre-test aims to verify that all items are understandable for a small sample and not necessarily representative of the population for which the tool is intended. It also seeks to capture information regarding response time.

At the end of this activity, a pilot tool can be applied to the entire student population and will be ready to have its psychometric properties assessed.

Application Procedure and Data Collection

For questions of applicability of the questionnaire and in relation to the cost and time for data collection, a sample size greater than 410 respondents is stipulated, which, according to (Pasquali, 2020) is a number of individuals required in studies involving factor analysis and must be greater than ten times the number of items.

After completing the steps of elaboration of the measurement tool, the form was applied online, generated in the free tool offered by Google: Google Forms, and also made available in the university's information system called SIGA-A. Students from all six institution campuses had access to the form for 15 days.

To analyze the characterization of the participants, the following information was collected: name, email, enrollment, campus or institute, undergraduate course, year of entry, IRA (Academic Performance Index), age, sex, and skin color/ethnicity.

Factor Analysis and Dimensionality

Exploratory and confirmatory factor analyses are typically used to assess the psychometric properties of the construct and are employed to investigate the dimensionality of a dataset (Reckase, 2009; Roff et al., 1997). Exploratory factor analysis (EFA) was performed at the beginning of the data analysis to determine the factor loading for each item and explore extractable factors, as well as verify whether the items are measuring one or more dimensions of the latent trait (Barbetta et al., 2014; Edwards et al., 2018; Pasquali, 2020).

The correlation matrix of items will be considered factorable when the Kaiser - Meyer - Olkin (KMO) value exceeds 0.5 and Bartlett's test is significant. The main axis factorization method will be applied to extract factors from which those with eigenvalues above 1 have been retained. Varimax rotation was applied to optimize the factor loading of each item on the extracted factors. Items with factor loadings greater than \pm 0.4 were selected for confirmatory factor analysis (CFA) (Childs \& Oppler, 2000; Wirth \& Edwards, 2007).

The determination of the number of dimensions, mainly regarding the choice of the analysis model, can typically be done in 4 ways: tetrachoric correlation matrix, parallel analysis, full information analysis, and empirical validation. In this analysis, we were interested in assessing the dimensionality of the 41 items that make up the questionnaire. 
The basic principle for assessing the dimensionality of a test follows the logic: the assumption of local independence is assessed under a hypothesized unidimensional or multidimensional model, and measures are obtained to indicate the amount of dependence between the items (Wei, 2008). If the dependency between items is stronger than would be expected by chance, the assumption of local independence is suspect. If there is a strong dependency between the items, the assumed dimensionality of the model will be rejected.

In this approach, local independence is defined as homogeneous or weak, and item dependencies are calculated based on the conditional covariances of item responses for all item pairs and at all latent trait levels. In this case, when unidimensionality conditions are satisfied for a given test and a specific population, differences in test performance are attributed to differences in individuals (Bonifay, 2019; Whitely, 1980; Wirth \& Edwards, 2007).

The first assessment was conducted using the restricted information method and consisted of an inspection of the eigenvalues of the tetrachoric correlation matrix. Then, the method of parallel analysis of restricted information, based on tetrachoric correlation, was applied.

Finally, dimensionality was assessed by applying multidimensional models, in particular, assessing data for 2 dimensions. Besides, the comparison of these models can be made by factor loadings and commonality, by analysis of variance (ANOVA) given by measures of AIC, BIC, and p-value, or by statistics that assess the quality of fit of the models given by the RMSEA (root mean square error of approximation) is recommended to be less than 0.06 , CFI (comparative fit index), and TLI (Tucker-Lewis index) and a value greater than 0.90 is recommended. Furthermore, these last statistics are not very sensitive to the sample size (Barbetta et al., 2014; Brown, 2015; Cai \& Hansen, 2013; Primi, 2010; Reckase, 2009).

Item Response Theory

Models derived from item response theory have been widely used in the literature. Specifically with applications in the educational area, psychological, and health assessments. Given its advantage over classical measurement theory, solid assumptions need to be made as to its applicability. Typically, two premises need to be strongly assessed: unidimensionality and local independence (Edwards et al., 2018).

Item Response Theory (IRT) is composed of a set of probabilistic models, which relate a latent trait of a respondent $(\theta)$, something that cannot be measured directly, with the respondent's probability of responding to an item within a given category (Lord, 2012). Items are generally classified as dichotomous, meaning that there are only two answer categories (commonly called "correct" and "incorrect"), or polytomous, meaning that the answers can be classified into several categories (Brossman \& Lee, 2010).

The IRT was originally developed in psychometrics to assess skills, mainly for educational purposes, to analyze items with correct and incorrect answers (De Ayala, 2013). However, the term 'item' is generic and 
as such applies to statements of attitude for which respondents are asked to indicate their level of agreement. IRT models the relationship between the likelihood of endorsing a particular response to an item and an individual's score on a latent (unmeasured underlying) trait (Giles et al., 2020; Hori et al.; Hori et al.; Kazemi \& Kajonius, 2021).

Unlike classical measure theory's test-level focus, IRT focuses on item performance. Thus, whereas CMT assumes that the test items are replicates of each other (i.e., parallel measurements), the IRT does not assume that the test items are equally difficult. Furthermore, in CMT is assumed that the score obtained by a person on a test is the sum of a true score and an error score. In contrast, in IRT, the probability that a given individual with a certain level of a specific characteristic has a level of that trait is determined by the person's true trait level and two measurement item parameters, i.e., discrimination and difficulty(Andrade et al., 2000).

The graded response model (Samejima, 1969) assumes that an item's response categories can be sorted against each other. This model tries to get more information from individuals' responses than simply giving correct or incorrect answers.

The concept of adequacy or perceived adequacy, in this work, refers to the idea of a search for criteria that measure the similarity between knowledge and the object that corresponds to it. Therefore, considering the remote educational environment, in which the student is inserted and incorporating the academic and social integration aspects of the longitudinal model of dropout of (Tinto, 1975), the proposed conceptual model hypothesizes that there is a set of factors that directly influence this environment and which, in turn, generates a negative, neutral, or positive perception associated with the quality of remote teaching. Thus, given the impact of these factors, the student's assessment will generate perceived adequacy worse, equivalent, or better than in onsite teaching to measure the quality of adequacy of emergency remote teaching.

In other words, (Andrade et al., 2000) suppose that an item's category scores $i$ are arranged in order from lowest to highest and denoted by $k=0,1, \ldots, m_{i}$ where $\left(m_{i}+1\right)$ is the number of categories of the $i$-th item. The probability of a respondent $j$ answering one or another higher value of the item $i$ can be given by the extension of the 2-parameter logistic model of the equation:

$$
P_{i, k}^{+}=\frac{1}{1+e^{a_{i}}\left(\theta_{j}-b_{i, k}\right)}
$$

With $i=1,2, \ldots, I, j=1,2, \ldots, n$, and $k=0,1, \ldots, m_{i}$, where:

$b_{i, k}$ is the difficulty parameter of the $k$-th category of the item $i$.

In the case of models for dichotomous items, the item slope parameter can be called item discrimination. However, in the case of models for non-dichotomous items, the discrimination of a specific response 
category depends both on the slope parameter, common to all item categories, and on the distance from the adjacent difficulty categories.

From the definition, we have:

$$
b_{i, 1}, b_{i, 2}, \ldots, b_{i, m_{1}}
$$

that is, there must necessarily be an ordering between the level of difficulty of the categories of a given item, according to the classification of its scores.

The probability of an individual $j$ receiving a score $k$ on the item $i$ is given by the expression:

$$
P_{i, k}\left(\theta_{j}\right)=P_{i, k}^{+}\left(\theta_{j}\right)-P_{i, k+1}^{+}\left(\theta_{j}\right) .
$$

(Samejima, 1969) also defines $P_{i, 0}^{+}\left(\theta_{j}\right)=1$ and $P_{i, m_{i}+1}^{+}\left(\theta_{j}\right)=0$, therefore,

$$
P_{i, 0}\left(\theta_{j}\right)=P_{i, 0}^{+}\left(\theta_{j}\right)-P_{i, 1}^{+}\left(\theta_{j}\right)=1-P_{i, 1}^{+}\left(\theta_{j}\right)
$$

and

$$
P_{i, m}\left(\theta_{j}\right)=P_{i, m}^{+}\left(\theta_{j}\right)-P_{i, m_{i}+1}^{+}\left(\theta_{j}\right)=P_{i, m}^{+}\left(\theta_{j}\right)
$$

So:

$$
P_{i, k}\left(\theta_{j}\right)=\frac{1}{1+e^{a_{i}\left(\theta_{j}-b_{i, k}\right)}}-\frac{1}{1+e^{a_{i}\left(\theta_{j}-b_{i, k}+1\right)}}
$$

Note that for an item with $\left(m_{i}+1\right)$ categories, $m_{i}$ difficulty values need to be estimated in addition to the item's slope parameter. Thus, the number of parameters to be estimated for each item will be given by its number of response categories. If, for example, we had a test with $I$ items, each with $\left(m_{i}+1\right)$ answer categories, then we will have $\left[\sum_{i=1}^{I} m_{i}+I\right]$ parameters to be estimated.

Tool's Internal Consistency

The precision of internal consistency is made possible through several statistical techniques that aim to verify the homogeneity of the sample of test items, that is, the test's internal consistency. The most used techniques in the literature, which will be used at this stage, are the test information function and Cronbach's alpha. All of them require the application of the test on a single occasion, totally avoiding the issue of temporal consistency (Pasquali, 2017). 


\section{Results And Discussion}

\section{Respondent Characterization}

The sample used in this study comprises 518 respondents, collected voluntarily. Furthermore, this total of respondents represent responses considered valid for analysis, having a number corresponding to the 41 responses of the measurement tool.

However, for profile analysis, there were indications in the questionnaire of wrong entry, not identified, or without entry, requiring that the treatment considers the proximity of the profile responses and the total number resulting in 509 valid responses. Thus, Figure 8 shows the age pyramid of respondents classified by gender and, there are a greater amount in the age group "20-24" years, which corroborates the premise of a younger profile and post-secondary education, with a higher quantity of "female" respondents for this age range.

The skin color/ethnicity survey was conducted based on self-declaration. As for the ethnic-racial profile of the respondents, there was a prevalence of brown color/ethnicity (66.5\%), followed by white (18.3\%) and white (13.8\%). The Asian color had only 6 indications and only 1 indigenous respondent. According to data from the 2019 National Household Sample Survey (PNAD), the North region presented in 2019, as the population, $72.2 \%$ declared brown, $7.3 \%$ black, $19.1 \%$ white, and $1.4 \%$ as Asian or indigenous.

The distribution by course resulted in 42 nominations corresponding to 19 courses and 6 campuses. To facilitate this classification, the courses were grouped into 8 major areas of CAPES that are presented in Figure 9.

There were more citations in Agricultural Sciences (47.64\%). It is consistent with the application context in which it has 8 related undergraduate courses and 17 of the 42 indications when analyzing the relationship with the campuses. Also, there is a characteristic of greater course load of practical and field activities in this area, that is, there is a demand for onsite activities. The other areas correspond to a complementary total of $52.36 \%$ and are characterized by the prevalence of course load in theoretical activities, that is, they have a better adaptability to remote teaching.

\section{Factor Analysis and Dimensionality}

The determination of the number of dimensions, mainly regarding the choice of the analysis model, can typically be done in 4 ways: tetrachoric correlation matrix, parallel analysis, full information analysis, and empirical validation. In this analysis, we are interested in assessing the dimensionality of the 41 items of the measurement tool.

The first assessment was conducted using the restricted information method and consisted of an inspection of the eigenvalues of the polychoric correlation matrix. It was considered factorable because the calculated value of $K M O=0.97>0.5$ and Bartlett's test was significant. In Table 2, the first ten eigenvalues of the matrix are presented. It is observed that the first eigenvalue is 19,695 and represents 
$48.04 \%$ of the explained variation of the set of 41 items. This value indicates unidimensionality, as there is no single dimension that significantly explains the use of two or more dimensions.

Table 2

- Eigenvalues of the tetrachoric correlation matrix, principal components, and factor analysis.

\begin{tabular}{|lllllllllll|}
\hline Dimension & $\mathbf{1}$ & $\mathbf{2}$ & $\mathbf{3}$ & $\mathbf{4}$ & $\mathbf{5}$ & $\mathbf{6}$ & $\mathbf{7}$ & $\mathbf{8}$ & $\mathbf{9}$ & $\mathbf{1 0}$ \\
\hline Eigenvalue & $\mathbf{1 9 . 7 0}$ & 1.86 & 1.46 & 1.33 & 1.25 & 1.13 & 0.91 & 0.88 & 0.81 & 0.75 \\
\hline $\begin{array}{l}\text { Cumulative proportion } \\
\text { of explained variation }\end{array}$ & $\mathbf{0 . 4 8}$ & 0.53 & 0.56 & 0.59 & 0.62 & 0.65 & 0.67 & 0.70 & 0.72 & 0.73 \\
\hline
\end{tabular}

Then, the method of parallel analysis of restricted information, based on tetrachoric correlation, was applied. In Figure 10, principal component analysis and factor analysis are presented to complement the dimensionality analysis. It is observed that for PC there is an indicative of 2 components and the FA indicates 6 factors and 2 components. However, there is a greater total variance explained by the first dimension, suggesting that they are methods that indicate the acceptance of unidimensionality. The graph indicates a strong latent trait, but it also indicates a second latent trait, that is, it suggests that the tool may be two-dimensional.

It is noteworthy that, empirically, the factors influence the academic environment, which, in turn, impacts the student's perception of remote teaching. This understanding is of paramount importance so that there is no direct interpretation between factors and dimensions. Given that unidimensionality was assumed, it was expected that the items would be converging to a single latent trait. Nevertheless, the data showed that there could be a second dimensionality.

The analysis of factor loadings and commonality has its results presented in Figure 11. Note that all items have a factor loading (F1) greater than 0.30 for 1 dimension, as suggested by (Pasquali, 2020), with the mean factor loadings being 0.669 and their values ranging from 0.449 (item 25) to 0.870 (item 45). The commonality (h2) is also acceptable in this set of items, ranging from 0.202 (item 25) to 0.757 (item 45 ) and a mean of 0.459 , indicating a good contribution to the measure.

Items 03,09 , and 25 have commonality values below 0.30 and indicate a smaller contribution to the measure. However, the decision on the maintenance or exclusion of these items will only be made together with the analysis by IRT.

It was then decided to assess the dimensionality by applying multidimensional models, particularly assessing the data for 1 and 2 dimensions. The comparison of models was performed by analysis of variance (ANOVA) given by the measures of AIC, BIC, and loglik, p-value (Table 3), and a twodimensionality is indicated. RMSEA, CFI, and TLI statistics were used in Table 4, in which the unidimensional model obtained a better RMSEA, TLI, and CFI. 
Table 3

Analysis of variance of the models.

\begin{tabular}{|lllll|}
\hline Models & AIC & BIC & Log-likelihood & p-value \\
\hline 1 dimensional model & $49,237.63$ & $50,102.03$ & $-24,413.81$ & \\
\hline 2 dimensional model & $\mathbf{4 8 , 7 3 9 . 5 1}$ & $\mathbf{4 9 , 7 7 2 . 5 8}$ & -24.124 .76 & 0 \\
\hline
\end{tabular}

Table 4

Fit analysis of the models.

\begin{tabular}{|llll|}
\hline Dimensions & RMSEA & TLI & CFI \\
\hline 1 dimensional model & $\mathbf{0 . 0 6 1 8 1 9}$ & $\mathbf{0 . 9 5 0 0 4 4 8}$ & $\mathbf{0 . 9 5 2 9 8 3 4}$ \\
\hline 2 dimensional model & 0.067861 & 0.9454207 & 0.9517635 \\
\hline
\end{tabular}

In summary, in the analyses conducted in this section, we can assume that a unidimensional structure can model the measurement tool because, when the tool and those assessed have more than one dimension, and these dimensions are correlated, the unidimensional model can be used (Reckase, 2009).

Item Analysis

Analyzing the slope parameter, a value below 1 , which indicates low discriminating power, was not found in the set of items and is associated with an understanding that respondents vary adequately well in terms of their latent trait, as shown in Figure 6. Items with a response frequency below 30 were regrouped, unifying the best-related responses. However, there was no improvement in the discrimination of these items.

In addition to the slope parameter estimate, the difficulty parameters are presented in Figure 13 . There is only an estimated error value close to 0.40 for the parameter $b_{1}$ of item 09 , which is an acceptable value given its higher estimated value.

Finally, in the analysis using the item characteristic curve (ICC), it is expected that the curves for each response category are more likely at some point on the scale. Items 08,25 , and 36 could have the categories ( 0 - much worse adequacy and 1 - worse adequacy) grouped, and item 30 grouped the categories ( 3 - better adequacy and $4-$ much better adequacy). Thus, an analysis of the quality fit of the models whose values are $R M S E A=0.060336, C F I=0.9528851$, and $T L I=0.9556407$ and do not represent significant improvements was performed.

The estimates of the slope parameters also showed a small estimated difference. Nevertheless, to interpret the students' perspectives, the categories that do not present a point on the scale with the highest probability must be removed in the construction of the scale.

Internal consistency 
Using the collected responses, the unidimensional model with regrouping was fitted to assess maximum reliability and what can be understood as the ideally weighted sum calculated from the items. The value obtained as the coefficient of determination for the first model was $C D=0.9712571$, indicating that the model is highly reliable and results in a good enough explanation based on the data. Other reliability values were also assessed, such as Cronbach's alpha coefficient $\alpha=0.9657675$, omega $\omega=0.9664525$, and the average variance extracted, $A V E=0.4229779$, also indicating an excellent precision.

The overall precision of the tool scores was also analyzed using the information function of the IRT test, the result of which is shown in Figure 14. In the interval between - 1.5 (associated with a perceived negative loss of teaching quality) and 2.5 (referring to an association of positive perception), the Information curve $I(\theta)$ is higher and the error associated with the measurement in this region is smaller. The slope $\operatorname{SE}(\theta)$ increases outside this range, which means that the item set is invalidated for these response levels.

In summary, we have enough evidence to accept that the latent trait is well modeled by a unidimensional structure, given the set of responses and items assessed. Thus, this analysis makes it possible to demonstrate that the set of calibrated items has evidence of reliability and can be used to build the scale of students' perceived adequacy of remote teaching.

Scale construction

All item parameters and latent traits of respondents were obtained in the same metric, represented in the scale $(0,1)$. However, in this work, a linear transformation was performed, and the scale was built with the metric $(0,10)$. This transformation is intended to facilitate the understanding and use of the measurement tool.

The first procedure for defining the scale is to identify the anchor levels, characterized by sets of anchor items, which are the points on the staircase that will be interpreted. Two criteria were adopted for the positioning of each item on the scale: [1] items that obtained estimates of the slope parameter for $a \geq 1$ and; [2] an item category will be an anchor at a certain scale level if at least it is answered by more than $60 \%$ of students with the same latent trait level.

Figure 15 presents the frequency distribution of the latent traits of the 501 students and the positioning of each category of items on the scale. It is observed that the profile associated with a perceived negative loss of teaching quality, represented by the parameter $b_{1}$ are positioned at levels below -10 and refer to $11.97 \%$ of students. These levels indicate that respondents are more likely to respond to the answer category ( 1 - worse adequacy) than the previous category $(0-$ much worse fitting) for the corresponding items.

At level -5 , respondents begin to present a profile associated with a perceived equivalence but are more strongly associated with a worse adequacy category with $17.37 \%$ of respondents. At the levels $(0 e 5)$, 
they are more likely to position themselves at a level of equivalence where there is a predominance of parameters $b_{2}$ and refer to $45.91 \%$. At the levels 10,15 and 20 , with $20.17 \%$ of respondents, anchor items associated with the parameter $b_{3}$ are observed, indicating that respondents are more likely to respond to the category ( 3 - better adequacy) than ( 2 - equivalent adequacy). Finally, for students positioned at levels higher than 25 (parameter $b_{4}$ ) has $4.4 \%$ of students and is associated with a positive perceived gain in teaching quality. 
Table 5

- Scale Interpretation.

\begin{tabular}{|c|c|c|c|c|}
\hline $\begin{array}{l}\text { Associated } \\
\text { Perception } \\
\text { Level }\end{array}$ & $\begin{array}{l}\text { Level of } \\
\text { Adequacy } \\
\text { of Remote } \\
\text { Teaching }\end{array}$ & Range & $\%$ & Description of Levels \\
\hline \multirow[t]{2}{*}{$\begin{array}{l}\text { Negative } \\
\text { Loss }\end{array}$} & $\begin{array}{l}\text { Much } \\
\text { worse } \\
\text { adequacy }\end{array}$ & $\begin{array}{l}(-30 ;-25] \\
(-25 ;-20] \\
(-20 ;-15]\end{array}$ & $\begin{array}{l}0.6 \% \\
1.0 \% \\
2.59 \%\end{array}$ & $\begin{array}{l}\text { At this level, the respondent has the } \\
\text { perception that remote teaching has } \\
\text { much worse adequacy and that there is a } \\
\text { negative association with a loss of } \\
\text { teaching quality. In addition, the } \\
\text { respondent relates the loss of quality to } \\
\text { aspects of the availability of materials, } \\
\text { class preparation, and access to remote } \\
\text { content. }\end{array}$ \\
\hline & $\begin{array}{l}\text { Worse } \\
\text { adequacy }\end{array}$ & $\begin{array}{l}(-15 ;-10] \\
(-10 ;-5]\end{array}$ & $\begin{array}{l}7.78 \% \\
17.37 \%\end{array}$ & $\begin{array}{l}\text { At this level, besides those described } \\
\text { above, the respondent has a worse } \\
\text { perceived adequacy, related to the } \\
\text { relationship and interaction with the } \\
\text { professor, professor accessibility, } \\
\text { organization of contents, classes, and, } \\
\text { topics, and assessment activities (mainly } \\
\text { concerning online tests). }\end{array}$ \\
\hline $\begin{array}{l}\text { Neutral } \\
\text { equivalence }\end{array}$ & $\begin{array}{l}\text { Equivalent } \\
\text { adequacy }\end{array}$ & $\begin{array}{l}(-5 ; 0] \\
(0 ; 5]\end{array}$ & $\begin{array}{l}24.95 \% \\
20.76 \%\end{array}$ & $\begin{array}{l}\text { At this level, the student perceives } \\
\text { equivalent adequacy in a considerable } \\
\text { number of items, considering different } \\
\text { aspects, such as accessibility, } \\
\text { concentration, tools/support offered to } \\
\text { the university, own resources, and } \\
\text { personal motivation. }\end{array}$ \\
\hline \multirow[t]{2}{*}{$\begin{array}{l}\text { Positive } \\
\text { gain }\end{array}$} & $\begin{array}{l}\text { Better } \\
\text { adequacy }\end{array}$ & $(10 ; 15]$ & $11.18 \%$ & $\begin{array}{l}\text { At this level, the student has a perception } \\
\text { of better adequacy, in a considerable } \\
\text { number of items, considering different } \\
\text { aspects, such as flexibility of study } \\
\text { schedules, group work, and relationship } \\
\text { with the coordination, incentives from } \\
\text { professors and family, interaction with } \\
\text { colleagues and contribution of remote } \\
\text { teaching, and professional training. }\end{array}$ \\
\hline & $\begin{array}{l}\text { Much } \\
\text { better } \\
\text { adequacy }\end{array}$ & $\begin{array}{l}(25 ; 30] \\
(30 ; 35]\end{array}$ & $0.6 \%$ & $\begin{array}{l}\text { At this level, the student has a much } \\
\text { better perceived adequacy, in a } \\
\text { considerable number of items, } \\
\text { considering different aspects, such as } \\
\text { relationship, interaction, and accessibility } \\
\text { to the professor, as well as organization } \\
\text { of contents and classes. }\end{array}$ \\
\hline
\end{tabular}

\section{Conclusions}


This work aimed to develop, build, and validate a measurement tool to measure the perception of students regarding the adequacy of remote teaching offered by the Federal Rural University of the Amazon (UFRA), to the detriment of classroom teaching adopted before the new context. Besides, we sought to demonstrate the methodological steps for constructing and validating this tool. Once the study is completed, the goals have been achieved, thus contributing to the assessment of teaching quality using psychometric measures.

The proposed methodological steps are ways to build this type of tool to help measure psychological constructs, especially students' perceptions. They can thus be used to contribute to the construction of new tools in other regions. In addition, the evidence of validity based on content was satisfactory and presented for the content validity index with a mean of $94.16 \%$ of acceptance per item and values above $93.43 \%$ of acceptance for the factors and domains.

Consequently, by presenting a conceptual structure of the main concepts, terms and expressions used within the context of Emergency Remote Teaching, after factor analysis and dimensionality, it was possible to assume that the measurement tool can be modeled by a unidimensional structure and by item analysis, there is enough evidence for adopting a unidimensional model, without disregarding the possibility of using a two-dimensional model, which is a recommendation for future studies.

For validation based on the internal structure, we have that the general precision of the tool scores obtained a Cronbach's alpha coefficient, whose value obtained was $96.64 \%$, indicating an excellent precision. Besides the coefficient, the precision of the tool was analyzed through the information function of the IRT test, whose result is comprised in the range between ( $-1.5 \mathrm{and} 2.5)$ approximately. Thus, the analysis of the main indicators that refer to a good quality of the measurement tool indicated a good quality of the construct.

One of the main contributions of this study, a standardized measurement scale was created with the metric $(0,10)$ from 501 respondents for profile levels associated with a perceived negative loss, equivalence, and a positive gain in teaching quality.

In summary, the respondent who relates the loss of quality associated with the availability of materials, class preparation, access to remote content, the relationship and interaction with the professor, accessibility of professors, organization of contents, classes, and topics, and assessment activities (mainly concerning online tests). At the level of perceived equivalent adequacy, it is associated with different aspects, such as accessibility, concentration, tools/support offered to the university, own resources, and personal motivation.

Finally, at the level of positive perception, different aspects, such as flexibility in study schedules, group work, and relationship with the coordination, incentives from professors and family, interaction with colleagues and contribution from remote teaching, professional training, relationship, interaction, and accessibility to the professor, as well as the organization of content and classes. 
Consequently, this psychological attribute can be understood as a measure of the latent trait of assessing the quality of adequacy of the emergency remote teaching offered, which, in turn, is not something directly identifiable or observable. Thus, the elaboration and validation of this construct is enough to manifest the indirectly observed reality through the variables or factors that can be observed and that are related to the subject of interest being measured.

It can also be said that this research is an attempt to apprehend some aspects that involve remote teaching. As for the limitations, it can be reported that some items for the assessment of remote teaching were not considered, aspects that can be referenced in other research with the same object of study. On the other hand, given the application of the IRT to the presented context, it was possible to incorporate useful information into the students' perception analyses that seek to identify adequacy characteristics and positively assess the quality of the construct.

For future studies related to IRT, it is indicated: [1] the application of multidimensional models (Bonifay, 2019; Reckase, 2009) for interpretation focusing on modeling the interaction between respondents, items, and dimensions; [2] validation of items through DIF (Differential Item Functioning) and aiming to differentiate people with the same latent trait derived from the fact that they belong to different groups (Belzak \& Bauer, 2020; Thissen et al., 1993; Vermunt \& Magidson, 2021) and [3] Graded Unfolding model (GGUM) in which the individual tends to agree with the item as it is located close to their personal position on the latent trait scale to which they were applied both in the development of behaviors and attitudes (DeMars \& Erwin, 2003; Scherbaum et al., 2006) and in the development of personality scales (Chernyshenko et al., 2007; Stark et al., 2006).

Finally, this study achieved both proposed objectives, both methodological and practical, and recognizes the limitations deriving from the little quantitative information on the subject and the little use of applied probabilistic models. As a perspective for new applications, it is indicated that the tool is improved, and the tool is applied to a number of university students to cover more regions and more universities. This attempt is fundamental for universities to build scientifically validated indicators through psychometrics.

\section{Declarations}

\section{Availability of data and materials}

The data sets used and/or analyzed during the current study are available from the corresponding author on reasonable request.

\section{Funding}

Not applicable.

\section{Competing interests}

The authors declare that they have no competing interests. 


\section{Acknowledgments}

The authors thank the Federal Rural University of the Amazon for assisting the preparation of this manuscript, the students involved in the focus groups and the execution of the pre-test, and the judges for their contributions.

Obs: The section included author affiliations information.

\section{Authors' Contributions}

Fernandes, R. S. and Sousa, J. C. C.: Conceptualization; Data curation; Formal analysis; Investigation; Methodology; Project administration; Resources; Software; Supervision; Validation; Visualization; Roles/Writing - original draft; Writing - review \& editing; Luz, R. M. N; Reis, D. C.; Luz, M. A. L.; Guimarães, G. V.; Bornia, A. C. and Andrade, D. F.: Formal analysis; Validation; Visualization; Roles/Writing - original draft; Writing - review \& editing.

\section{Ethical Approval}

The research followed the National Health Council Resolution No. 466, of December 12, 2012. Thus, the free and informed consent form was applied, guaranteeing the confidentiality and ethics of research involving human beings. This research was approved by the ethics committee according to opinion No. CAAE 46373021.6.0000.5110.

\section{References}

1. Aguilera-Hermida, A. P. (2020). College students' use and acceptance of emergency online learning due to COVID-19. International Journal of Educational Research Open, 1, 100011. https://doi.org/https://doi.org/10.1016/j.ijedro.2020.100011

2. Ali, W. (2020). Online and remote learning in higher education institutes: A necessity in light of COVID-19 pandemic. Higher education studies, 10(3), 16-25. https://doi.org/https://doi.org/10.5539/hes.v10n3p16

3. Ambiel, R. A. (2015). Development of the Reasons for Higher Education Dropout Scale. Avaliação Psicológica, 14(1), 41-52. https://doi.org/https://doi.org/10.15689/ap.2015.1401.05

4. Andrade, D. F., Tavares, H. R., \& da Cunha Valle, R. (2000). Teoria da Resposta ao Item: conceitos e aplicações. ABE, Sao Paulo

5. Barbetta, P. A., Trevisan, L. M., Tavares, H., \& de Azevedo, M., T. C. A (2014). Aplicação da Teoria da Resposta ao Item uni e multidimensional. Estudos em Avaliação Educacional, 25(57), 280-302. https://doi.org/https://doi.org/https://doi.org/10.18222/eae255720142832

6. Belzak, W., \& Bauer, D. J. (2020). Improving the assessment of measurement invariance: Using regularization to select anchor items and identify differential item functioning. Psychological methods, 25(6), 673. https://doi.org/https://doi.org/10.1037/met0000253 
7. Bonifay, W. (2019). Multidimensional item response theory. Sage Publications

8. Brossman, B. G., \& Lee, W. C. (2010). Book Review: Mark D. Reckase, Multidimensional Item Response Theory. New York, NY: Springer. 2009. 354 pp. Applied Psychological Measurement, 34(8), 641-645. https://doi.org/https://doi.org/10.1177/0146621610377761

9. Brown, T. A. (2015). Confirmatory factor analysis for applied research. Guilford publications

10. Burleson, S. E., \& Thoron, A. C. (2014). Maslow's hierarchy of needs and its relation to learning and achievement. Gainesville: Department of Agricultural Education and Communication

11. Buttler, T., George, D., \& Bruggemann, K. (2021). Student input on the effectiveness of the shift to emergency remote teaching due to the COVID crisis: Structural equation modeling creates a more complete picture. International Journal of Educational Research Open, 2, 100036. https://doi.org/https://doi.org/10.1016/j.ijedro.2021.100036

12. Cai, L., \& Hansen, M. (2013). Limited-information goodness-of-fit testing of hierarchical item factor models. British Journal of Mathematical and Statistical Psychology, 66(2), 245-276. org/10.1111/j.2044-8317.2012.02050.x. https://doi.org/https://doi.org/https://doi.

13. Cavalheiro, F. R. S., \& Sticca, M. G. (2020). Adaptation and Validation of the Brazilian Version of the Fear of COVID-19 Scale. International Journal of Mental Health and Addiction, 1-9. https://doi.org/https://doi.org/10.1007/s11469-020-00415-9

14. Chernyshenko, O. S., Stark, S., Drasgow, F., \& Roberts, B. W. (2007). Constructing personality scales under the assumptions of an ideal point response process: Toward increasing the flexibility of personality measures. Psychological assessment, 19(1), 88.

https://doi.org/https://doi.org/10.1037/1040-3590.19.1.88

15. Childs, R. A., \& Oppler, S. H. (2000). Implications of test dimensionality for unidimensional IRT scoring: An investigation of a high-stakes testing program. Educational and Psychological Measurement, 60(6), 939-955. https://doi.org/https://doi.org/10.1177/00131640021971005

16. Chiou, P. Z. (2020). Learning cytology in times of pandemic: an educational institutional experience with remote teaching. Journal of the American Society of Cytopathology, 9(6), 579-585. https://doi.org/https://doi.org/10.1016/j.jasc.2020.05.004

17. Coluci, M. Z. O., Alexandre, N. M. C., \& Milani, D. (2015). Construction of measurement instruments in the area of health. Ciência \& Saúde Coletiva, 20, 925-936. https://doi.org/https://doi.org/10.1590/1413-81232015203.04332013

18. De Ayala, R. J. (2013). The theory and practice of item response theory. Guilford Publications

19. De la Fuente, C. I., Guadagnin, E. C., Kunzler, M. R., \& Carpes, F. P. (2021). Programming course for health science as a strategy to engage students during the coronavirus pandemic. Advances in Physiology Education, 45(1), 53-58. https://doi.org/https://doi.org/10.1152/advan.00183.2020

20. DeMars, C., \& Erwin, T. D. (2003). Revising the scale of intellectual development: Application of an unfolding model. Journal of College Student Development, 44(2), 168-184.

https://doi.org/https://doi.org/10.1353/csd.2003.0013 
21. Edwards, M. C., Houts, C. R., \& Cai, L. (2018). A diagnostic procedure to detect departures from local independence in item response theory models. Psychological methods, 23(1), 138. https://doi.org/https://doi.org/10.1037/met0000121

22. Giles, S., Fletcher, D., Arnold, R., Ashfield, A., \& Harrison, J. (2020). Measuring well-being in sport performers: where are we now and how do we progress? Sports Medicine, 50(7), 1255-1270. https://doi.org/https://doi.org/10.1007/s40279-020-01274-z

23. Gorenstein, C., \& Wang, Y. P. (2016). Fundamentos de mensuração em saúde mensal. In Instrumentos de avaliação em saúde mental. Artmed. https://observatorio.fm.usp.br/handle/OPI/20832

24. Hodges, C. B., Moore, S., Lockee, B. B., Trust, T., \& Bond, M. A. (2020). The difference between emergency remote teaching and online learning. http://hdl.handle.net/10919/104648

25. Hofer, S. I., Nistor, N., \& Scheibenzuber, C. (2021). Online teaching and learning in higher education: Lessons learned in crisis situations. Computers in Human Behavior, 121, 106789. https://doi.org/https://doi.org/10.1016/j.chb.2021.106789

26. Hori, K., Fukuhara, H., \& Yamada, T. Item response theory and its applications in educational measurement Part I: Item response theory and its implementation in R.Wiley Interdisciplinary Reviews: Computational Statistics,e1531. https://doi.org/https://doi.org/ https://doi.org/10.1002/wics.1531

27. Hori, K., Fukuhara, H., \& Yamada, T. Item response theory and its applications in educational measurement Part II: Theory and practices of test equating in item response theory.Wiley Interdisciplinary Reviews: Computational Statistics,e1543. https://doi.org/https://doi.org/10.1002/wics.1543

28. Iglesias-Pradas, S., Hernández-García, Á., Chaparro-Peláez, J., \& Prieto, J. L. (2021). Emergency remote teaching and students' academic performance in higher education during the COVID-19 pandemic: A case study. Computers in Human Behavior, 119, 106713. https://doi.org/https://doi.org/10.1016/j.chb.2021.106713

29. Kazemi, A., \& Kajonius, P. (2021). Assessing person-centred care: An item response theory approach. International Journal of Older People Nursing, 16(1), e12352. https://doi.org/https://doi.org/10.1111/opn.12352

30. Lord, F. M. (2012). Applications of item response theory to practical testing problems. Routledge

31. Marasca, A. R., Yates, D. B., Schneider, A. M., d., A., Feijó, L. P., \& Bandeira, D. R. (2020). Avaliação psicológica online: considerações a partir da pandemia do novo coronavírus (COVID-19) para a prática e o ensino no contexto a distância. Estudos de Psicologia (Campinas), 37. https://doi.org/Psychological assessment online: repercussions of the new coronavirus (COVID-19) pandemic on remote practice and distance teaching

32. Mohmmed, A. O., Khidhir, B. A., Nazeer, A., \& Vijayan, V. J. (2020). Emergency remote teaching during Coronavirus pandemic: the current trend and future directive at Middle East College Oman. Innovative Infrastructure Solutions, 5(3), 1-11. https://doi.org/https://doi.org/10.1007/s41062-02000326-7 
33. Moser, K. M., Wei, T., \& Brenner, D. (2021). Remote teaching during COVID-19: Implications from a national survey of language educators. System, 97, 102431.

https://doi.org/https://doi.org/10.1016/j.system.2020.102431

34. Newton, P. E. (2017). There is more to educational measurement than measuring: The importance of embracing purpose pluralism. Educational Measurement: Issues and Practice, 36(2), 5-15. https://doi.org/https://doi.org/10.1111/emip.12146

35. Nickel, E. M., Ferreira, M. G. G., Forcellini, F. A., Santos, C. T., \& Silva, R. A. (2010). Á. Multicriteria model as a reference in the informational design stage of the product development process. Gestão \& Produção, 17, 707-720. https://doi.org/https://doi.org/10.1590/S0104-530X2010000400006

36. Pasquali, L. (2017). Psicometria: teoria dos testes na psicologia e na educação.Editora Vozes Limitada. https://examen.emnuvens.com.br/rev/article/view/19

37. Pasquali, L. (2020). TRI-Teoria de resposta ao item: Teoria, procedimentos e aplicações. Editora Appris

38. Primi, R. (2010). Psychological assessment in Brazil: foundations, current situation and future directions. Psicologia: teoria e pesquisa, 26, 25-35. https://doi.org/https://doi.org/10.1590/S010237722010000500003

39. Quispe-Prieto, S., Cavalcanti-Bandos, M. F., Caipa-Ramos, M., Paucar-Caceres, A., \& Rojas-Jiménez, H. H. (2021). A Systemic Framework to Evaluate Student Satisfaction in Latin American Universities under the COVID-19 Pandemic. Systems, 9(1), 15. https://doi.org/https://doi.org/10.3390/systems9010015

40. Reckase, M. D. (2009). Multidimensional item response theory models. In Multidimensional item response theory (pp. 79-112). Springer. https://doi.org/https://doi.org/10.1007/978-0-387-89976-3_4

41. Ribeiro, H. C. M., \& Corrêa, R. (2021). Teaching strategies practiced in private higher education institutions of an educational group in brazil in the face of the covid-19 pandemic. Revista Gestão Organizacional, 14(1), 333-355. https://doi.org/https://doi.org/10.22277/rgo.v14i1.5658

42. Roff, S., McAleer, S., Harden, R. M., Al-Qahtani, M., Ahmed, A. U., Deza, H. ... Primparyon, P. (1997). Development and validation of the Dundee ready education environment measure (DREEM). Medical teacher, 19(4), 295-299.

https://doi.org/https://doi.org/https://doi.org/10.3109/01421599709034208

43. Samejima, F. (1969). Estimation of latent ability using a response pattern of graded scores.Psychometrika monograph supplement. https://psycnet.apa.org/record/1972-04809-001

44. Scherbaum, C. A., Finlinson, S., Barden, K., \& Tamanini, K. (2006). Applications of item response theory to measurement issues in leadership research. The Leadership Quarterly, 17(4), 366-386. https://doi.org/https://doi.org/10.1016/j.leaqua.2006.04.005

45. Secundo, G., Gioconda, M., Del Vecchio, P., Gianluca, E., Margherita, A., \& Valentina, N. (2021). Threat or opportunity? A case study of digital-enabled redesign of entrepreneurship education in the COVID19 emergency. Technological forecasting and social change, 166, 120565.

https://doi.org/https://doi.org/10.1016/j.techfore.2020.120565

Page 23/32 
46. Shim, T. E., \& Lee, S. Y. (2020). College students' experience of emergency remote teaching due to COVID-19. Children and youth services review, 119, 105578. https://doi.org/https://doi.org/10.1016/j.childyouth.2020.105578

47. Sindhu, I., Daudpota, S. M., Badar, K., Bakhtyar, M., Baber, J., \& Nurunnabi, M. (2019). Aspect-based opinion mining on student's feedback for faculty teaching performance evaluation. IEEE Access, 7 , 108729-108741. https://doi.org/https://doi.org/10.1109/ACCESS.2019.2928872

48. Stark, S., Chernyshenko, O. S., Drasgow, F., \& Williams, B. A. (2006). Examining assumptions about item responding in personality assessment: Should ideal point methods be considered for scale development and scoring? Journal of Applied Psychology, 91(1), 25. https://doi.org/https://doi.org/10.1037/0021-9010.91.1.25

49. Thissen, D., Steinberg, L., \& Wainer, H. (1993). Detection of differential item functioning using the parameters of item response models. https://doi.org/https://doi.org/10.1075/z.62.13kok

50. Tinto, V. (1975). Dropout from higher education: A theoretical synthesis of recent research. Review of educational research, 45(1), 89-125. https://doi.org/https://doi.org/10.3102/00346543045001089

51. Vermunt, J. K., \& Magidson, J. (2021). How to perform three-step latent class analysis in the presence of measurement non-invariance or differential item functioning. Structural Equation Modeling: $A$ Multidisciplinary Journal, 28(3), 356-364.

https://doi.org/https://doi.org/10.1080/10705511.2020.1818084

52. Wei, Y. (2008). A simulation study on the performance of four multidimensional IRT scale linking methods. University of Florida

53. Whitely, S. E. (1980). Multicomponent latent trait models for ability tests. Psychometrika, 45(4), 479494

54. Whittle, C., Tiwari, S., Yan, S., \& Williams, J. (2020). Emergency remote teaching environment: a conceptual framework for responsive online teaching in crises. Information and Learning Sciences. https://doi.org/https://doi.org/10.1108/ILS-04-2020-0099

55. Wirth, R., \& Edwards, M. C. (2007). Item factor analysis: current approaches and future directions. Psychological methods, 12(1), 58. https://doi.org/https://doi.org/10.1037/1082-989X.12.1.58

\section{Figures}

\section{Figure 1}

Latent Trait conceptual model. 


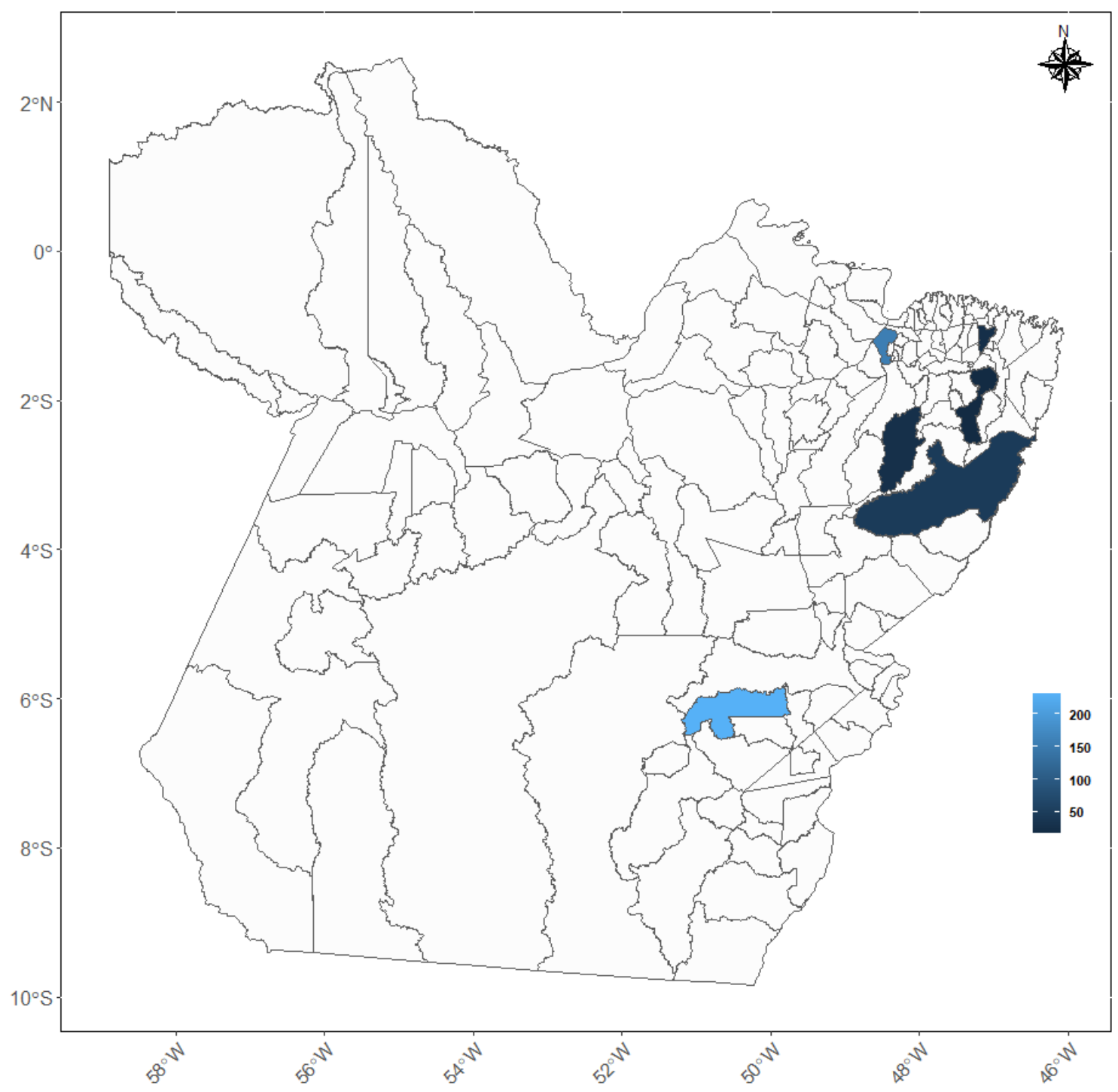

Figure 2

Figure 3. Representation map of responses distributed by campus. 


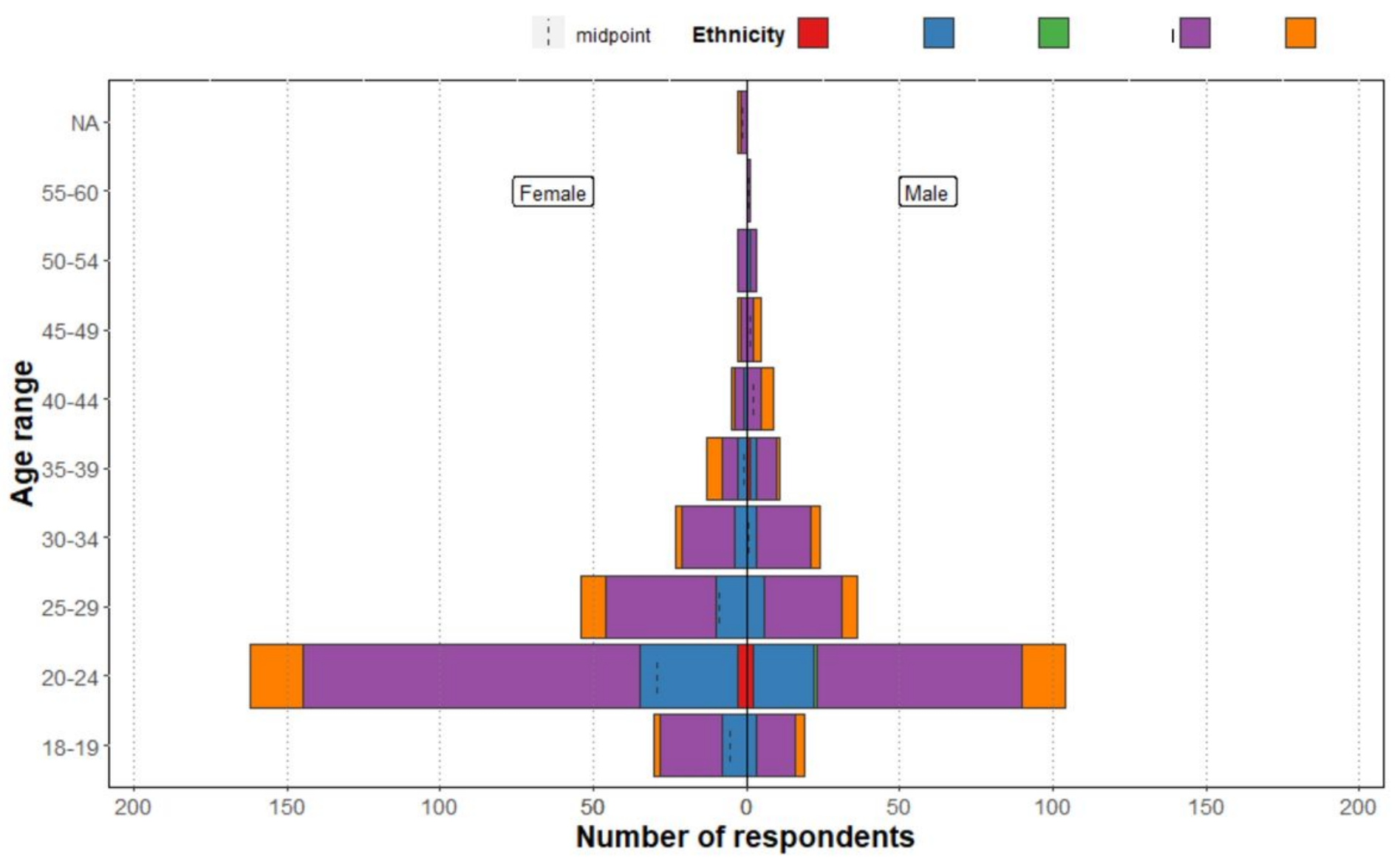

Figure 3

Figure 8. Age pyramid for respondents by sex.

Figure 4

Figure 9. Distribution of the number of students by major area of CAPES. 
Parallel Analysis Scree Plots

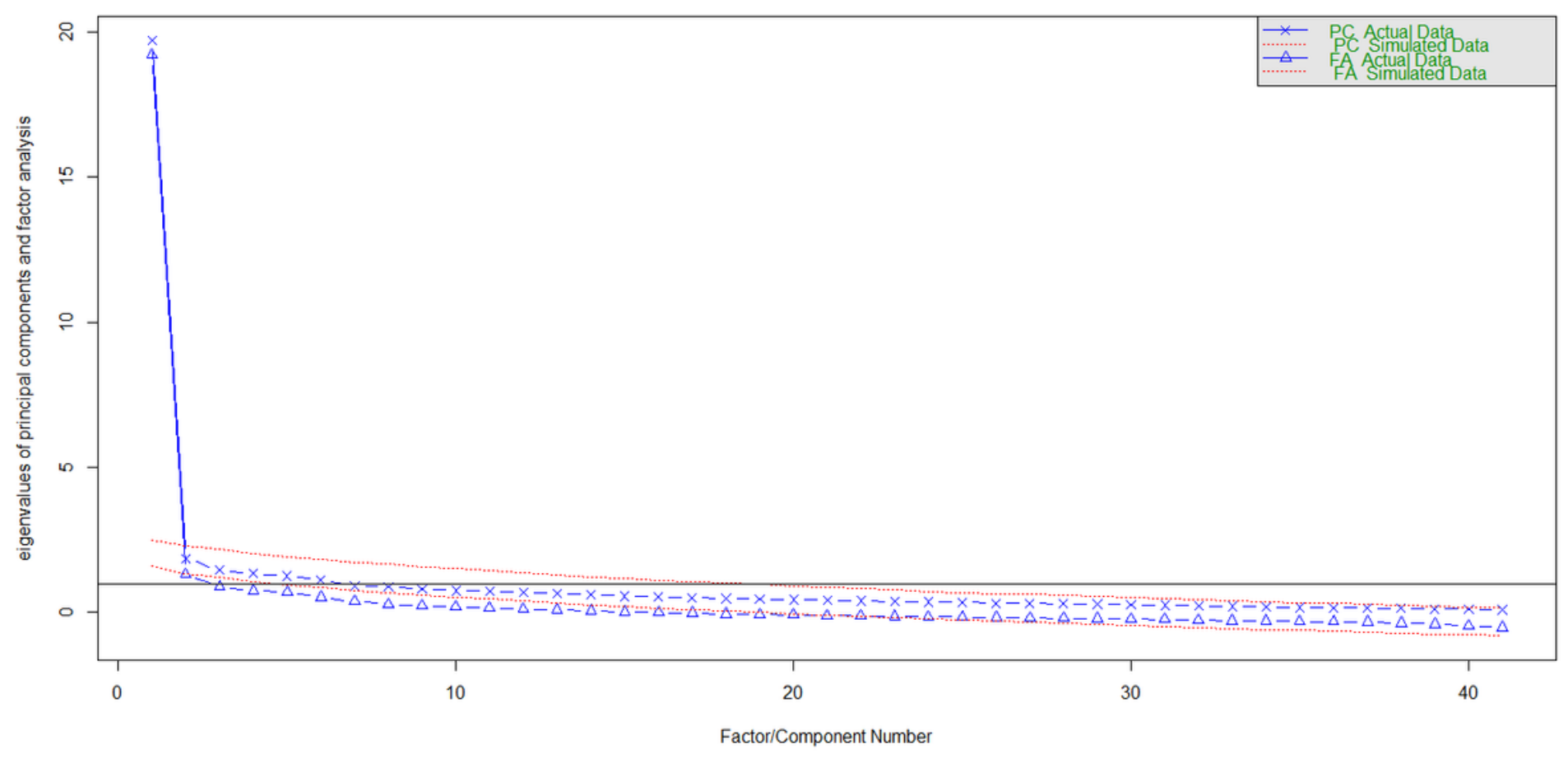

Figure 5

Figure 10. Principal component analysis and factor analysis. 


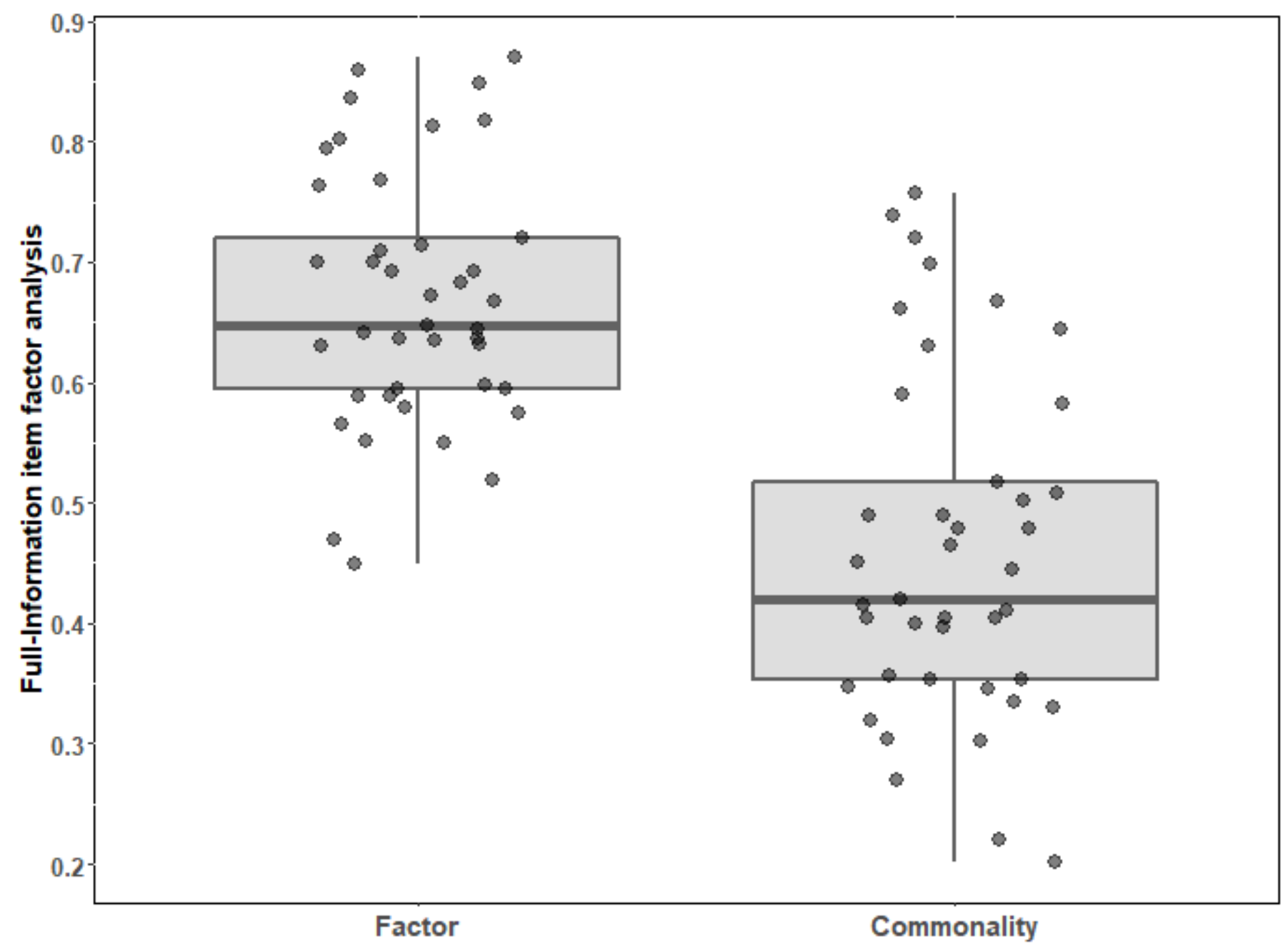

Figure 6

Figure 11. Factor loadings and commonalities of the 41 items of the measuring tool for 1 and 2 dimensions. 


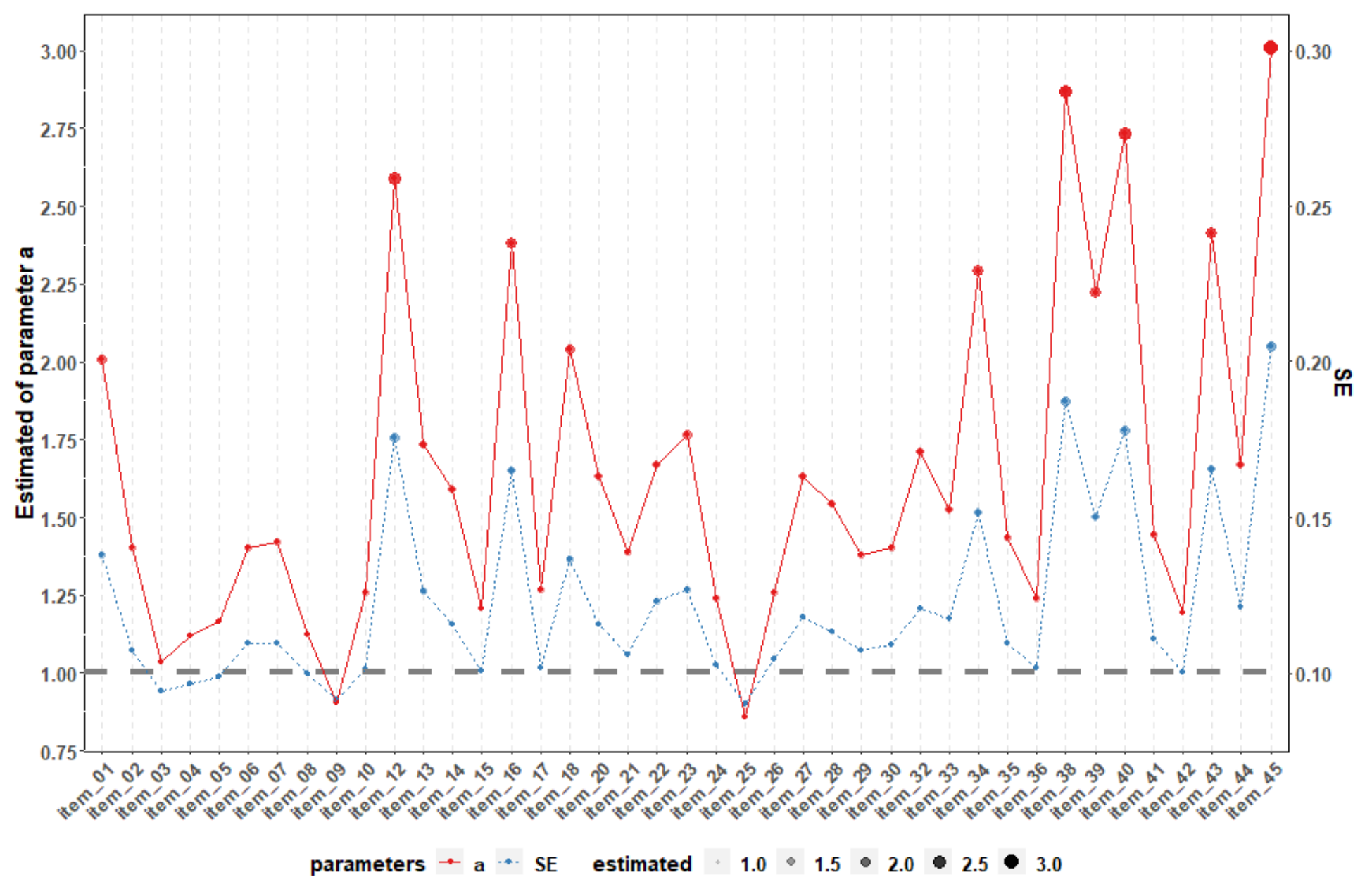

Figure 7

Figure 12. Estimate of the slope parameters of the items on the scale $(0,1)$. 


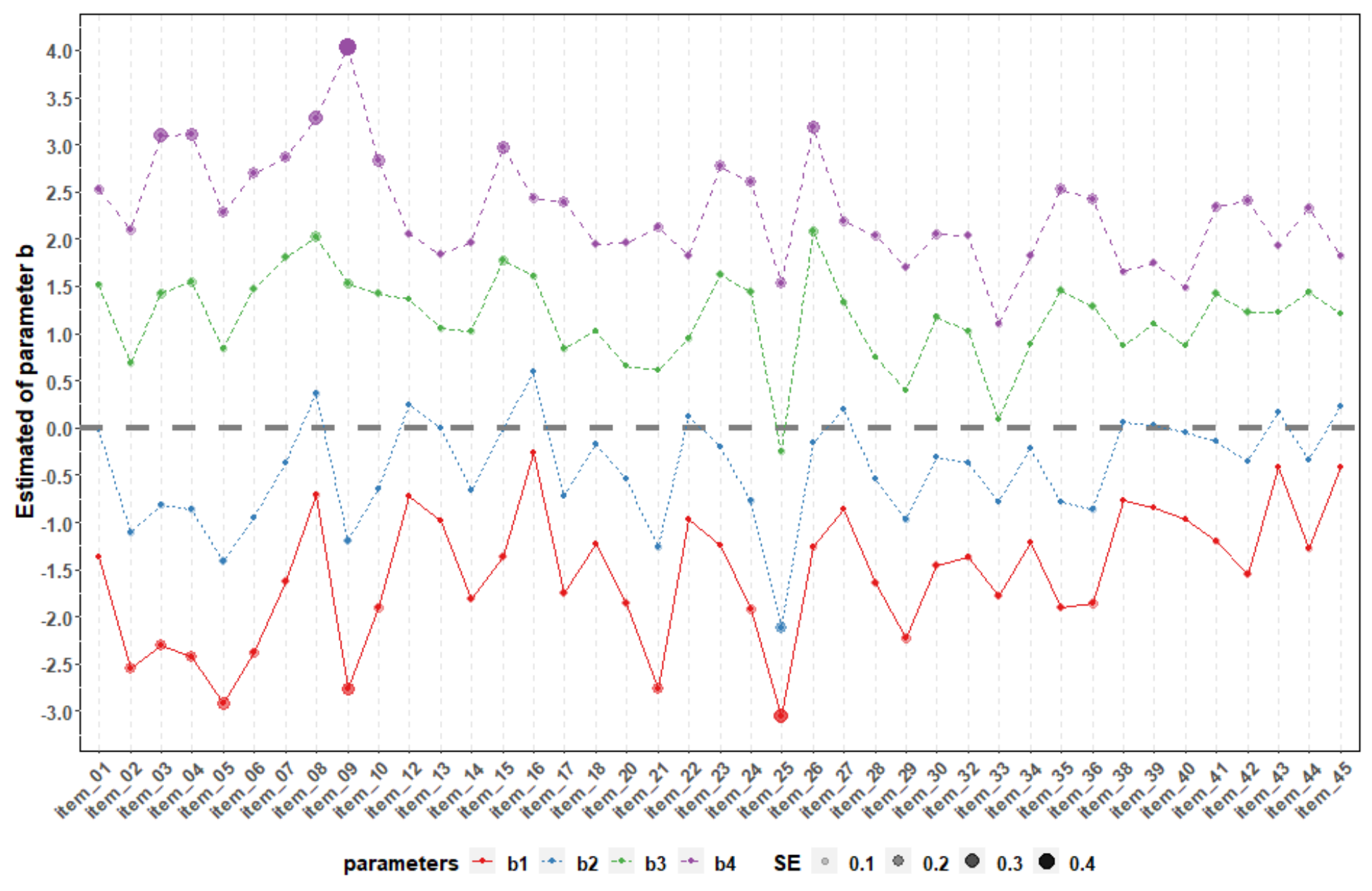

Figure 8

Figure 13. Estimate of the difficulty parameters. 
Test Information and Standard Errors

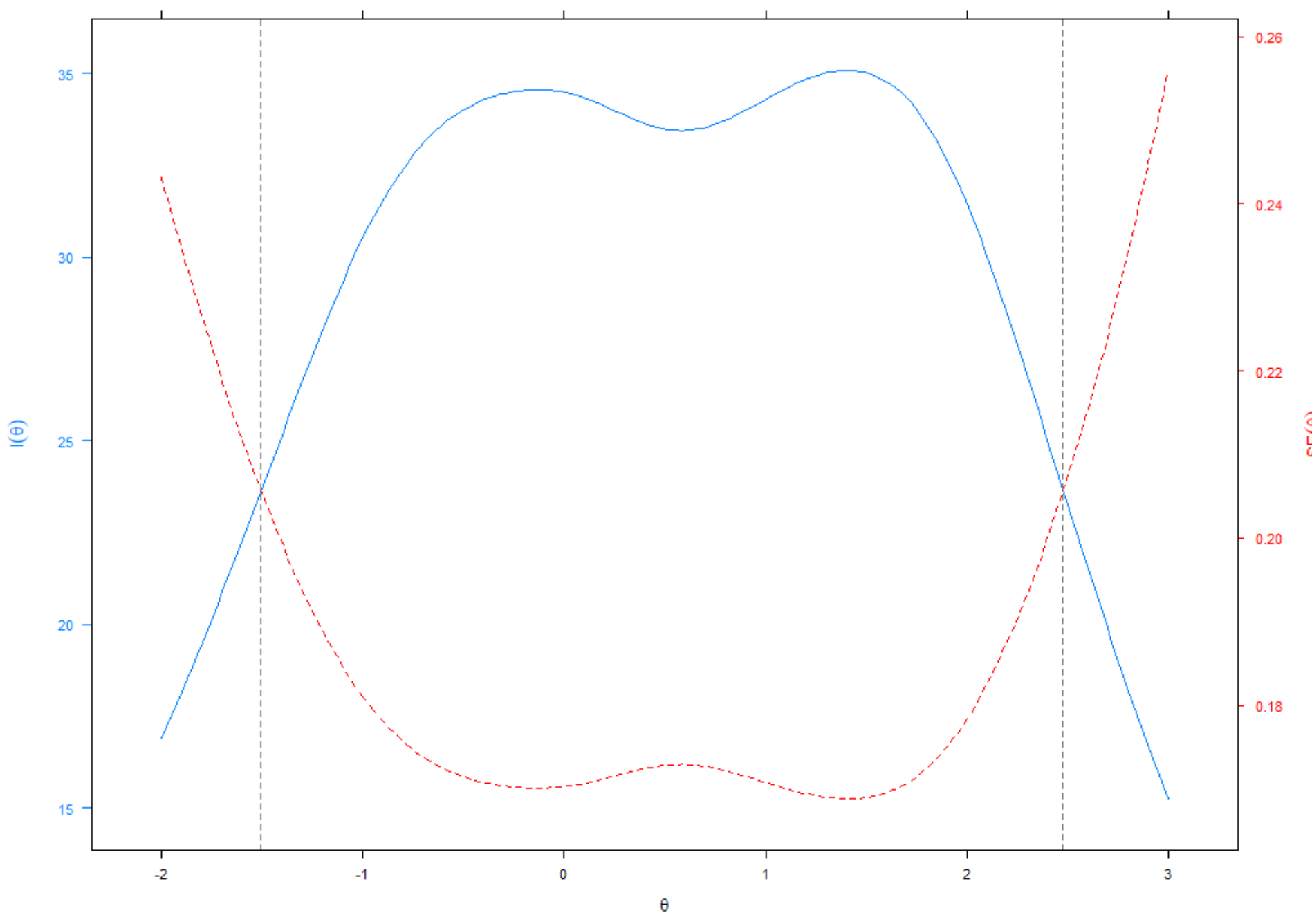

Figure 9

Figure 14. Test information and standard errors. 


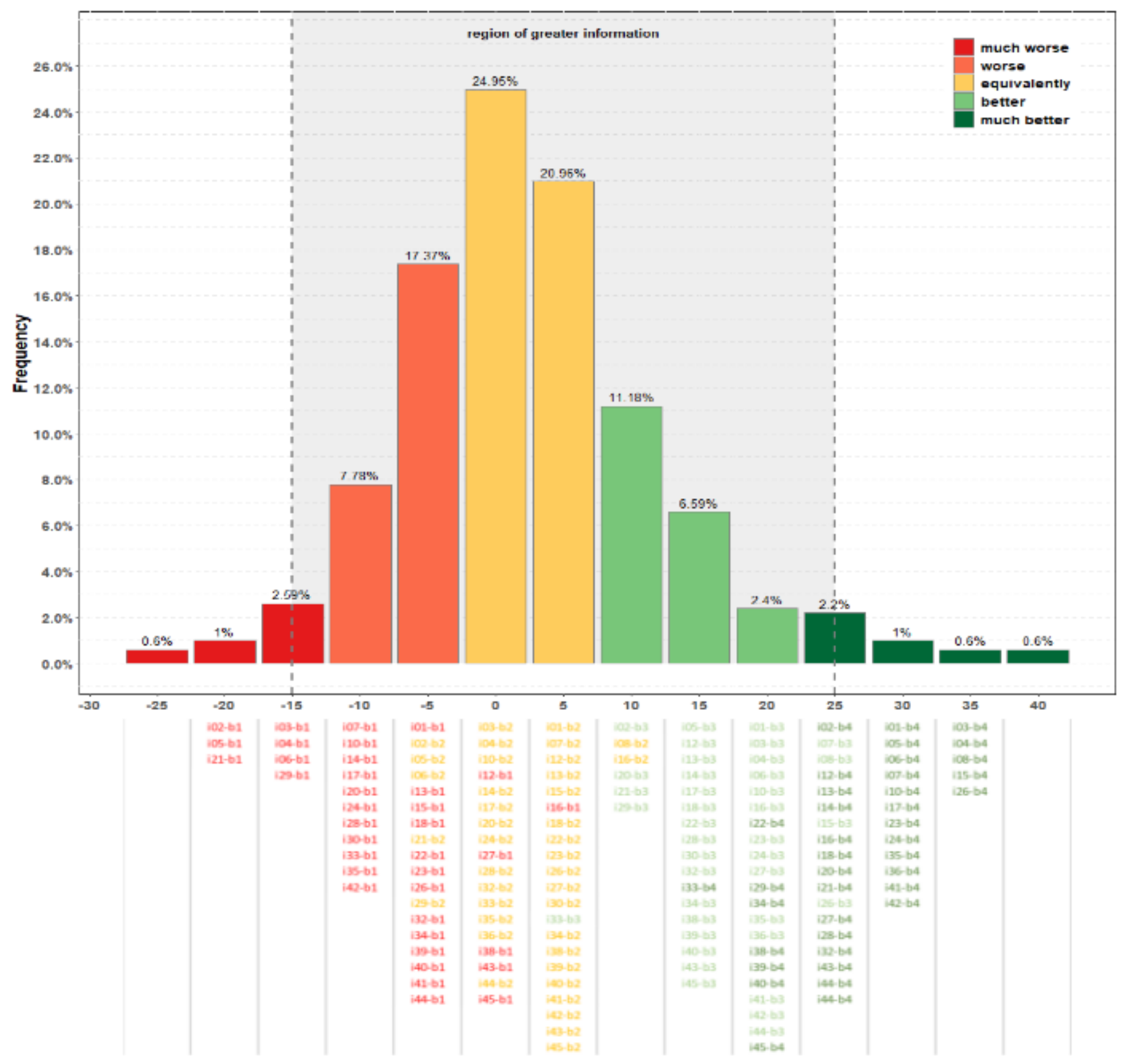

Figure 10

Figure 15. Positioning of item categories and distribution of latent trait values of the 501 respondents on the scale.

\section{Supplementary Files}

This is a list of supplementary files associated with this preprint. Click to download.

- Appendice.docx 